\title{
CARNAVALIZAÇÃO E COMPLEXIDADE TURÍSTICA: FORMAÇÃO DE PAISAGENS RITUAIS EM EVENTOS NO ESTADO DO CEARÁ
}

\author{
Carnavalization and touristic complexity: \\ Construction of rituals landscapes in events in the State of \\ Ceará
}

\author{
Christian Dennys Monteiro de OLIVEIRA ${ }^{1}$
}

\begin{abstract}
RESUMO
O estudo da formação metropolitana de novos santuários, na cultura religiosa brasileira, tem despertado interessantes discussões na Geografia contemporânea. Um enfoque pouco explorado a respeito é a necessidade de transformar as manifestações de fé em espetáculos, para os devotos e os visitantes. Neste trabalho, a investigação dessa tendência dá-se na observação dos processos que tornam esses rituais eventos espetaculares. Seja na construção de uma estética que imita a grandiosidade do carnaval brasileiro, seja no atendimento às demandas turísticas advindas dessa imitação. Refletindo sobre os mecanismos dessa carnavalização, o estudo acompanha em primeiro lugar as festas dos padroeiros e santos populares na cidade de Fortaleza e em importantes cidades do interior do estado do Ceará. Em uma segunda parte, é feita a abordagem a respeito dos aspectos turísticos que envolvem o crescimento desses eventos. O que demonstra o complexo jogo de interesses na valorização dos espaços urbanos ocupados por essas manifestações e a importância de interpretar a representação cultural dessa pratica turística com ferramentas teóricas inovadoras.
\end{abstract}

Palavras-chave: Complexidade; Espetáculo; Religiosidade; Turismo.

\begin{abstract}
The study of the formation of new metropolitan shrines, in the Brazilian religious culture, has aroused interesting discussions in contemporary geography. The need to transform the expressions of faith in shows has been little explored for the cautious and visitors. In this work, the investigation of this trend is in the observation of processes that make these rituals spectacular events. In the construction of an aesthetic that imitate the greatness of the Brazilian carnival, or in the service to the demands of this emerging touristic imitation. Reflecting on the mechanisms that carnavalization, the study tracks firstly the festivities of the patron saints and popular in the city of Fortaleza in major cities in the interior of the state of Ceará. In a second part, it made the approach about the tourist aspects involving the growth of these events. This shows the complex game of interests in the exploitation of urban spaces which comes out from these events and the importance of interpreting the representation of this cultural practice tourism with innovative theoretical tools.
\end{abstract}

Keywords: Complexity; Spectacle; Religiosities; Tourism.

1 Professor Adjunto da Universidade Federal do Ceará, Pós-Doutor em Turismo pela Escola de Comunicações e Artes da Universidade de São Paulo e Pesquisador do Laboratório de Estudos Geoeducacionais, integrado aos Programas de Pós-Graduação em Geografia e Avaliação de Políticas Públicas, ambos na UFC e Colaborador do Centro de Estudos Latino Americano sobre Cultura e Comunicação (CELACC-ECA-USP). 


\section{INTRODUÇÃO}

O presente artigo corresponde aos resultados preliminares de uma investigação sistemática das interfaces de dois fenômenos contemporâneos em franca integração metropolitana: a religiosidade e a turistificação. Estudos anteriores a respeito dos processos de modernização de espaços simbólicos (sagrados e profanos) permitiram a reorganização desta pesquisa exploratória, na qual tem sido possível refletir e compreender o seguinte fenômeno. De que maneira a cultura metropolitana de Fortaleza consegue "carnavalizar" suas manifestações religiosas mais expressivas mesmo sem a projeção regional ou nacional de suas festividades carnavalescas? E por que razões os fatores que condicionam esse santuário metropolitano permanecem à margem da visibilidade turística?

Partindo desses questionamentos, o trabalho discute a formação das paisagens rituais em Fortaleza, por intermédio de uma hermenêutica das imagens híbridas (jornalísticas e empíricas), a fim de retratar a dinamismo das festas religiosas (São José, N. S. de Fátima, Iemanjá, Assunção, etc.) e a diluição dos eventos profanos (o carnaval, o forró, a festa junina). Tudo em favor de uma hibridação cultural - simbólica e materialmente espacializada - na construção de difusa de novos santuários. O grande problema é tentar percebê-los e registrá-los apenas pelos fixos; quando constatamos que está na fluidez sua maior identidade. Os meios (cartográficos, fotográficos e iconográficos) utilizados para desencadear essa hermenêutica precisam suceder a uma breve reflexão metodológica a respeito do processo científico em diálogo permanente com o imaginário mítico-religioso.

A pesquisa acadêmica lança um permanente desafio ao pesquisador contemporâneo: como tornar as investigações científicas um veículo de leitura do cotidiano? Pode parecer arriscado e ambivalente iniciar uma reflexão sobre formas simbólicas, no âmbito da geografia do turismo, destacando as necessidades consumistas da comunicação escrita. Mas um pensamento complexo na geografia (SILVA; GALENO, 2004) com diretriz educacional, não pode furtar-se ao reconhecimento de que lidar com a ambivalência é tão científico quanto explorar a objetividade. O que recruta a interlocução, dois tipos de leitores, em geral insensíveis às mutações do imaginário religioso na geografia da sociedade brasileira. Tanto os estudiosos de ciências humanas quanto a militância das organizações ambientalistas, teimam em reduzir o peso cultura religiosa na interpretação dos problemas sociais e ambientais de um território. Entretanto, por fatos ou metáforas, esse mesmo cotidiano cria e recria novos equipamentos especiais de ritualização, aqui reconhecidos pelo codinome de Santuário.

O conhecimento das formas simbólicas - atualizadas pelo desafio da modernização do carnaval brasileiro - pode e deve pleno intercâmbio com os dilemas espaciais contemporâneos, dentro do contexto metropolitano. Os santuários rituais - com especial atenção para aqueles que ganham dimensão carnavalesca - firmam-se na reverência e na retórica das tradições, mas, exploram o que há de mais acessível e tecnológico na dinâmica dos espetáculos. Reflexo desafiador da composição de uma estratégia híbrida de modernização das localidades que requer a confluência permanente de elementos pré e pós- modernos. Para compreensão dessa confluência vale revisar a tipologia dos espaços simbólicos trabalhados na interpretação geográfica do Turismo.

\section{SANTUÁRIOS: LÓCUS DA PAISAGEM RITUAL CONTEMPORÂNEA}

O primeiro de estudo é recompor de forma instrumental e esquemática uma tipologia dos santuários na configuração dos espaços de motivação e destinação turística.

É preciso inicialmente considerar que uma geografia do turismo integrada à discussão dos espaços simbólicos, não se reduz à análise dos lugares turísticos receptivos e nem isola os fatores econômicos do trade como determinantes da invasão capitalista. Postulamos uma geografia que interpreta o fazer turístico como estratégia comunicativa de desenvolvimento; portanto, seu caráter relacional e educacional pode restringir-se ao conservadorismo das estruturas de poder vigente. Assim como também forjar um espaço de modificação e recomposição dessas mesmas estruturas. Para tanto, torna-se cada vez mais fundamental demonstrar a atividade turística em sua dimensão imaginária original. Isto é, como lugar de motivação, de emissão e de promoção dos deslocamentos. Há que se destacar e explorar a compreensão do turismo como recurso didático de comunicação dos lugares. O que é significativamente diferente de tratar os espaços turísticos na perspectiva ampliada dos resorts ou na oposição com os espaços populares autênticos.

A estratégia global da Igreja Católica Romana atribuiu esse papel educacional estratégico aos seus centros de peregrinação, assumidos ou reinventados como santuários religiosos oficiais. A partir dessa sen- 
sibilidade política de enfoque pedagógico, recuperamos a idéia expansionista dos santuários para dimensionar quatro modelos de ocorrência geográfica desse espaço simbólico na contemporaneidade. Passemos a apresentá-los (com exemplos) antes de nos fixarmos naquele que mais se associa à carnavalização.

Como tradicionais podem ser classificados os espaços sagrados pertencentes e reconhecidos diretamente por uma confissão religiosa (em especial, aqueles vinculados ao catolicismo popular). Denomina-se por tradicional todo o templo, capela e construção destinados a um serviço religioso especial, dentro da hierarquia dos ritos e cultos de determinada religião.

Os "santuários tradicionais" tendem, então, a corresponder a classe de lugares sagrados (incluindo sua extensão e/ou arredores profanos) identificados, no plano místico, pelo culto de uma divindade ou sua manifestação direta, desde que reconhecidos no interior de um sistema religioso. O peso histórico-institucional e a representação arquitetônica tornam esse tipo de santuário uma espécie de patrimônio dinâmico da religiosidade de um povo. Por conseguinte, confere às suas paisagens uma densidade simbólica primordial no reconhecimento do turismo religioso.

No Brasil, os santuários tradicionais são identificados com a força ordenadora do catolicismo. Embora presente na organização de outras confissões, o próprio conceito de santuário cristaliza-se na concepção judaico-cristã de terra santa (na escala nacional) ou lugar do santo (na local). Pelos exemplos a seguir, reconheceremos como os santuários tradicionais apenas reforçam nossa tradicional visão de turismo religioso como peregrinações e romarias (OLIVEIRA, 2004). Por outro constatamos que no Brasil, não há um planejamento regional turístico compatível para tamanha capacidade de atração de algumas localidades. Consideremos o convento ou basílica da Penha nos estados do Sudeste Brasileiro; ou mesmo as hierópolis (centros de peregrinação) de projeção internacional: Aparecida, Juazeiro do Norte, Fátima, Lourdes, Compostela, Meca, Salt Lake, Varanasi, entre tantas outras. Há também as cidades santuários com expressão regional nacionais: Congonhas do Campo - MG, Madre Paulina - SC, São Francisco de Canindé-CE, Trindade - MG; Pirapora do Bom Jesus - SP. Além de inúmeras localidades místicas relacionadas ao protestantismo petencostal, ao espiritismo e aos cultos afro-brasileiros. No estado do Ceará, como veremos, esse santuários servirão (em perspectiva ampliada) para sediar os eventos prioritariamente disponíveis como produto de turistificação.
O segundo grupo é o dos "santuários metropolitanos". Correspondem a ampliação material e espacial da idéia de terra santa; e, ao mesmo tempo, traduzem uma diluição do campo religioso no plano secular (mundano ou profano). As grandes metrópoles (ou megalópoles pelo contraste com seu entorno) contem, em seu tecido urbano, o cosmopolitismo mítico-religioso fundamental ao atendimento espiritual de suas diversas comunidades. Podem ser assim chamadas de santuários (como um todo ou por intermédio de suas localidades ícones). Não apenas por manter os mais variados tipos de templo e lugares de culto; mas justamente por viabilizarem as principais motivações (qualitativas e quantitativas) para o crescimento da religiosidade no mundo contemporâneo. Muitos são os exemplos de manifestações religiosas (convencionais ou renovadas) que não ganhariam terreno longe dos sistemas urbanos. Principalmente aqueles relacionados às redes de comunicação.

A metrópole é, por outro lado, um território de invenções e reinvenções da sacralidade. Nesse sentido, podemos até estudar os santuários tradicionais ignorando os processos contemporâneos de urbanização metropolitana. Entretanto, é fundamental reconhecer que o estudo dos santuários metropolitanos deve privilegiar os centros comerciais (shoppings), as praças e prédios monumentais ou mesmos os bairros de forte carga simbólica e cultural como espaços míticos, permanente abertos à sacralização. Nesse sentido, pode-se mesmo rejeitar a força mística que envolve uma visita ao Masp (São Paulo), ao Pelourinho (Salvador), ao Maracanã (Rio de Janeiro) ou às praças, monumentos e prédios referenciais. O Bairro de Iracema e a Praça do Ferreira, em Fortaleza, reproduzem uma aura semelhante. Mas não se pode negar que as heranças éticas e estéticas que coroam o simbolismo das sociedades contemporâneas continuam alimentando-se nas estratégias religiosas de persuasão espiritual. Eis porque observar as metrópoles como os maiores centro de peregrinação, ainda que disfarçados numa espécie de turismo profano. Nesse sentido, é que viabilizam uma condição de diversidade privilegiada para uma investigação a respeito dos processos de carnavalização. Consideramos, no Brasil, as cidades de São Paulo, Rio de Janeiro e Brasília - além das explosivas capitais nordestinas, como Fortaleza os melhores exemplos geográficos para esse tipo de investigação.

Mais difíceis de serem estudados como santuários e, contraditoriamente, mais fáceis de serem reconhecidos popularmente dentro dessa denominação, os "santuários naturais" formam esse terceiro grupo de investigação. Serras, praias, vales, matas e 
principalmente áreas marcantes de um ecossistema determinado (caatinga, mangue, floresta tropical) são rapidamente identificados como lugares paradisíacos. Ganham inclusive o status ecoturístico de santuário, tão somente pelo apelo imaginário que tem dominado esses verdadeiros bolsões de natureza "natural". Muito embora a constituição histórica dessa leitura do natural em tempos de crise ambiental esteja exigindo dos estudos geográficos um tratamento muito particular desse processo. Consideramos tais espaços mítico-religiosos um grande desafio para investigação na geografia do turismo. Primeiro porque as questões ambientais são freqüentemente vistas por sua dimensão materialista e mecânica, conforme nos lembra Enrique Leff (2001), limitando a sistematização de uma saber ambiental. Quando se projetam outros aspectos não materialistas, o preconceito científico passa a rotular tais abordagens como ocultismo esotérico. Além disso, na tradição judaico-cristã - preponderante no mundo ocidental - os espaços naturais foram identificados, na Terra, como uma espécie de "ilusão" do Reino de Deus. Portanto, tomados como idílicos e perigosos. Daí a necessidade de transformar o paraíso num inferno, como nos mostrou toda a história dos territórios coloniais. O inferno, nesse sentido telúrico, é um lugar produtivo: uma plantation de cana-de-açúcar, uma província mineradora (de diamantes e ouro), um povoado estratégico para conquista dos sertões, dos mais diferenciados sertões. Assim se trabalhou ao longo de séculos para descaracterizar a religiosidade intrínseca relação sociedade-natureza.

Nos últimos anos, no entanto, o questionamento dessa ruptura tem permitido um comportamento religioso nas lutas dos ativistas ambientais. As questões ecológicas, a legislação e a própria política conservacionista - criando áreas especiais de proteção - tem permitido a formação de parques, estações e reservas como ilhas de paraíso (jardins do éden!) em meio ao inferno. O que, em certa medida, também depende de estratégias espetaculares de sensibilização coletiva como os eventos ambientalistas multiplicados pelo mundo inteiro.

Uma investigação sistemática sobre o uso míticoreligioso de Unidades de Conservação (públicas e privadas), no Brasil e outros países é o foco de estudo proposto nesse tipo de santuário. De que forma deve-se considerar as forças da espiritualidade na luta em defesa da natureza? Eis uma maneira de abrir o problema.

Os "santuários rituais" são essencialmente móveis e sua presença está vinculada, predominantemente, a um dos outros modelos de santuários. É nesse modelo que sistematizamos a reflexão desse breve estudo, no vínculo com os santuários tradicionais e metropolitanos. As festas em geral - como manifestações religiosas, folclóricas, sacro-profanas ou cívicas - constituem o principal exemplo de tais santuários. Basicamente sua realização confere o retorno de um tempo sagrado (ELIADE, 2001). E independentemente da manutenção de suas características mais típicas, encontra-se na reprodução de suas etapas um misticismo que lhe é intrínseco e peculiar. Como lidar turisticamente com esse patrimônio imaterial sem o uma leitura mítico-religiosa de sua realização e o que nos parece absolutamente inconsistente.

Via de regra o Carnaval, a Festa Junina, as Folias de Santos e as Danças do Boi, no Brasil são interpretados como alvos permanentes de desvirtuamento e intromissão cultural. A própria reutilização desses costumes como atrativo turístico tem massificado essas visões extremistas, embora novas abordagens sobre a complexidade do campo cultural tenham aparecido na reflexão dos pesquisadores. Infelizmente ainda é dominante uma leitura que aprisiona a cultura popular entre a resistência artesanal e a massificação kitch.

As festividades, no entanto, permanecem e se multiplicam no tempo demonstrando uma riqueza proporcional ao que é representado pelo urbano no espaço. Da mesma maneira que se tornou impossível ignorar a dimensão mítico-religiosa das cidades, não se pode mais isolar as festas de sua motivação espiritual. Cumpri-nos, nesse quarto modelo, questionar: até que ponto a Umbanda redirecionou a celebração do Ano Novo? Como Círio de Nazaré adquiriu essa condição de carnaval santo? Os festivais da pesca e da colheita (da lagosta, de uva, do morango), nos diversos pólos agropecuários desse país, não nos sugere a remanescente idolatria das festas pagãs?

Forma-se aqui uma grande expectativa de análise geográfica do simbolismo mítico-religioso. Principalmente dos rituais que proporcionam muitas catarses individuais e coletivas. Todas movidas pela mesma obrigação do sacrifício e a mesma gratidão da sobrevivência cotidiana: a fé. Muito embora, uma fé sedimentada pela possibilidade (e necessidade) de transitar entre lugares, costumes e valores cada vez mais diversificados ou festivos. A fé forjada pelo que denominamos "religiosidade turística" mantém uma aliança tensa e ambígua com a modernidade. Observemos o esquema da Figura 01 para perceber a integração dos três modelos fixos de santuários (tradicionais, metropolitanos e naturais) com a dinâmica de fluxos dos santuários rituais. Seria 
a partir desse último - com paisagens descontínuas e potencialidades multiplicadas na lógica do turismo de eventos - que se estabelece a "necessidade" de reorganização das festividades locais em caráter espetacular. Tal compreensão da espacialidade contemporânea baseia-se na perspectiva de que o fenômeno religioso atua como um campo comunicacional de valores (MARTIN-BARBERO, 2003) que dão sentido transcendente a existência cotidiana (BELO, 1998; BAZAN, 2002).

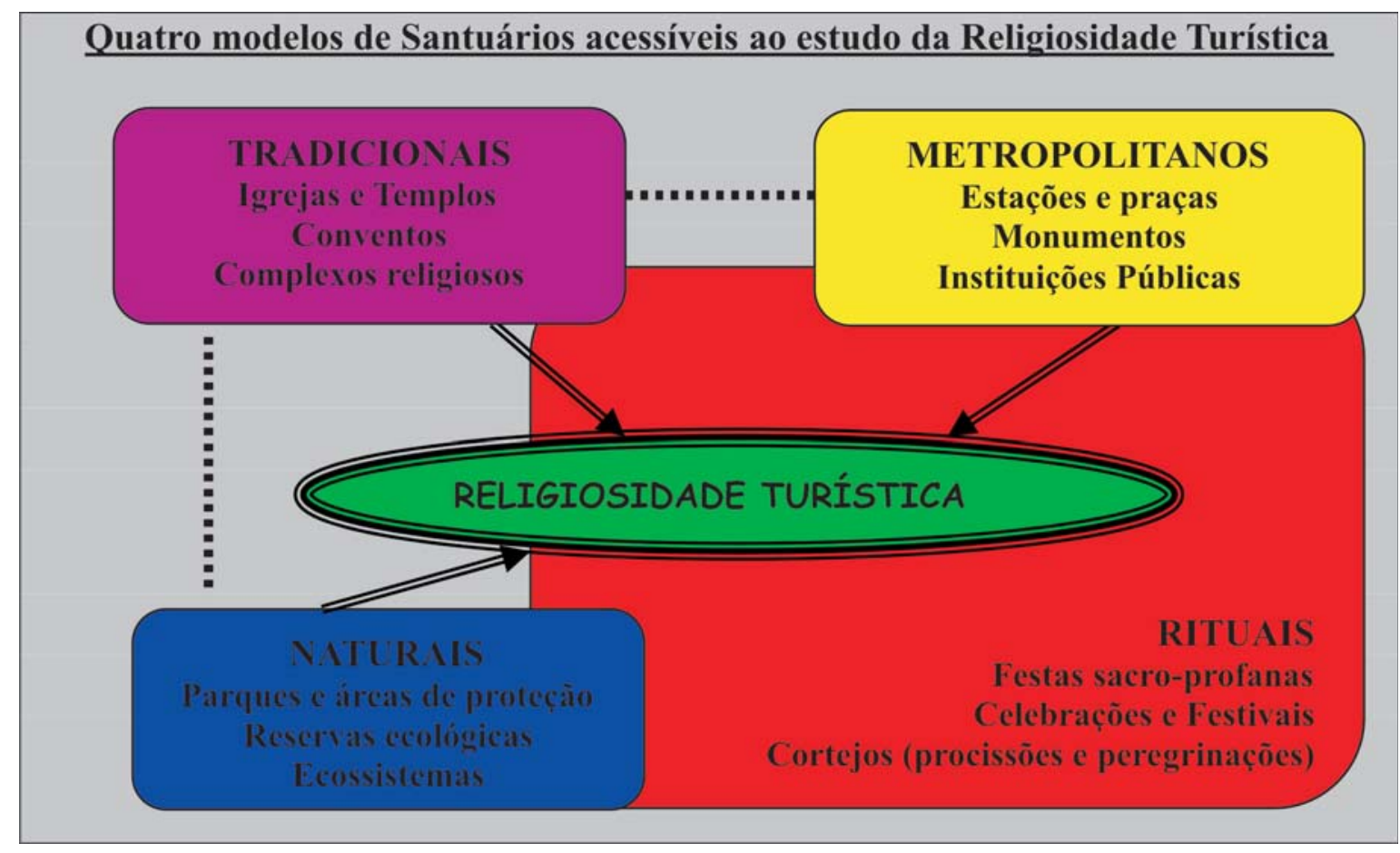

FIGURA 1 - ESQUEMA DE INTERLIGAÇÃO DOS MODELOS DE SANTUÁRIOS CONTEMPORÂNEOS

A característica fundamental de inter-relação dos quatro modelos está indiretamente relacionada à produção de uma religiosidade turística, posto que os fatores que alimentam tal "consumo ritual" permitem ao praticante uma adesão mais flexível às exigências dos cultos. Toda a discussão da sociologia da religião a respeito do mercado de bens sagrado, não se restringe aos sistemas religiosos tradicionais. Quando o fazem, fortalecem estruturas fundamentalistas. Mesmo, assim nossa hipótese diante da multiplicidade e variedade de festejos indica que os esquemas de adaptação carnavalesca das festas religiosas têm colaborado com valorização das localidades, em um período muito limitado para o êxito de políticas públicas territoriais.

\section{FESTAS RELIGIOSAS E CARNAVALIZAÇÃO}

A espacialização dos fenômenos e processos culturais, na Grande Fortaleza-CE, continua apresentando situações diversas e aparentemente desconexas. Eventos lúdicos, cívicos, esportivos, são transformados em shows populares de forte apelo simbólico. Especialmente aqueles que se enquadram como "eventos religiosos" - sejam nos ginásios, estádios, praças públicas ou parques - adquirem uma substantiva expressão cultural, embora à margem do planejamento turístico setorial ou regional. Um exemplo de grande relevância na capital são as comemorações do feriado de quinze de agosto. As festas no espaço público, de N. S. da Assunção e de Iemanjá, demarcando espaços do Catolicismo (oeste e centro da capital) e dos Terreiros de Umbanda (festejando na Praia do Futuro, zona leste). Esse "convívio" aparece como um dos mais completos exemplos de contrastes criativo da construção de um santuário ritual, com características carnavalescas.

É importante, antes de adentrarmos na caracterização panorâmica das festas religiosas cearenses (bem como em sua demarcação temporal e sazonal), delimitarmos quais os critérios que utilizamos metodologicamente para analisar o processo de carnavalização desses santuários. 
Considerando o carnaval popular em sua fase midiática como um modelo de exportação de estruturas rituais (OLIVEIRA, 2007), podemos apontar três variáveis representativas dessa carnavalização das festas religiosas:

a) A "projeção paisagística" da própria festa, com significativa visualidade (cenografia e figurinos) e visibilidade (alcance popular) facilitando a promoção da mesma como um evento expansionista;

b) A "criação de estruturas, serviços e representações" que fazem da festa um acontecimento territorialmente "consensual", comprometendo toda uma localidade, independentemente da confissão religiosa ou da concordância dos seus participantes;

c) A "demarcação de uma imagem cultural" com forte apelo turístico, embora - na maior parte das vezes - esse apelo se dê em caráter espontâneo, sem o devido planejamento técnico.

Daí ser tão pertinente estabelecer indagações que vinculem a pesquisa com o cotidiano das festividades e abrir linhas de intercâmbio, no território cultural, entre religiosidade, festividade e práticas comunicacionais de entretenimento e turismo. No Brasil - e em boa parte da América Latina - são essas três forças que dinamizam a ambiência cultural do Carnaval. Muito se explorou o seu significado temporal. Contudo, sua densidade espacial contém muitas lacunas.

Como fundamentação teórica, as análises antropológicas de Rita Amaral (2000) e político - comunicacional de Nazareth Ferreira (2001) estabeleceram um ponto de partida para leitura estratégica dessas festas (especialmente a de N. S. de Assunção - lemanjá). Outras reflexões sobre a evolução histórica do carnaval brasileiro, no decorrer dos séculos XIX e XX, aparecem como demonstração de sua marca modelar e organizativa (QUEIROZ, 1992; TRAMONTE, 2001; ARAUJO, 2003) e produto de exportação da imagem nacional (BIGNAMI, 2002), Mas é na reconstrução contemporânea, como espetáculo de mídia (e turístico) para toda e qualquer época do ano, que se evidencia a sua "profanação" essencial. Embora, o geógrafo Felipe Ferreira, "a instauração do Carnaval esteja intrinsecamente ligada à instauração da tensão por sua hegemonia e pela disputa do lugar carnavalesco." (FERREIRA, 2005, p. 322), como pensar a valorização estratégica do modelo carnavalesco na religiosidade sem a contrapartida do cristianismo secular?

Investigar o processo de carnavalização dos santuários e a densidade de suas manifestações como sínteses da contemporaneidade metropolitana, constitui o principal objetivo deste trabalho. Em termos específicos, os objetivos permitiram o desenvolvimento das três partes apresentadas nos parágrafos seguintes. Cumpre, no entanto, lembrar que os procedimentos metodológicos da pesquisa - até o presente - demarcaram as seguintes atividades: a) Revisão bibliográfica a respeito da modernização das festas e do carnaval; b) indicação das manifestações populares de interface religiosa, na área em estudo (a capital cearense); c) registro dos depoimentos sobre a organização desses eventos; d) caracterização paisagística dos elementos (quantitativos e qualitativos) do processo de carnavalização da Festa de quinze de agosto; e) reflexão sobre a (des) articulação desses eventos em relação ao planejamento do turismo na metrópole.

\section{AS FESTIVIDADES SACRO-PROFANAS NO ESTADO DO CEARÁ}

Uma demarcação precipitada dos eventos religiosos tradicionais tenderia a caracterizar o processo de carnavalização como uma efetiva "exceção" que confirma a regra: a religiosidade popular tem demonstrado uma das poucas resistências culturais ao processo de globalização dos costumes e valores. Mas a pesquisa em curso tende a contribuir com a inversão dessa leitura, evitando, portanto, a precipitação das imagens aparentes. Se é verdade que a solidariedade comunitária, as lideranças familiares e conjuntura sempre limitada dos recursos marcam o padrão de montagem dessas festas; também é fundamental observar a crescente solidificação dos laços institucionais que fazem do evento festivo uma prioridade estratégica (no bairro, no distrito ou na cidade). Dessa constatação se depreende bases elementares para explicar como as elites (políticas, econômicas, intelectuais e eclesiais), encontram na carnavalização da festa uma justificativa racional e afetiva para conduzi-la, não a "qualquer preço". Mas no custo necessário para o "retorno" do capital simbólico investido. E nessa hora a interface desse investimento com a visibilidade turística da festa - mesmo sem o apelo turístico do lugar - torna-se um instrumental compatível com a retórica da sustentabilidade do investimento. Quem nessa hora vai afirmar que a festa do distrito, muito mais onerosa que o previsto é um evento insustentável?

Com base no site oficial do governo do estado do Ceará, efetuamos a modelação de dois gráficos preliminares. Um de caráter temporal, relacionando meses do ano e incidência das festas religiosas apontadas. 
Vejamos o gráfico resultante:

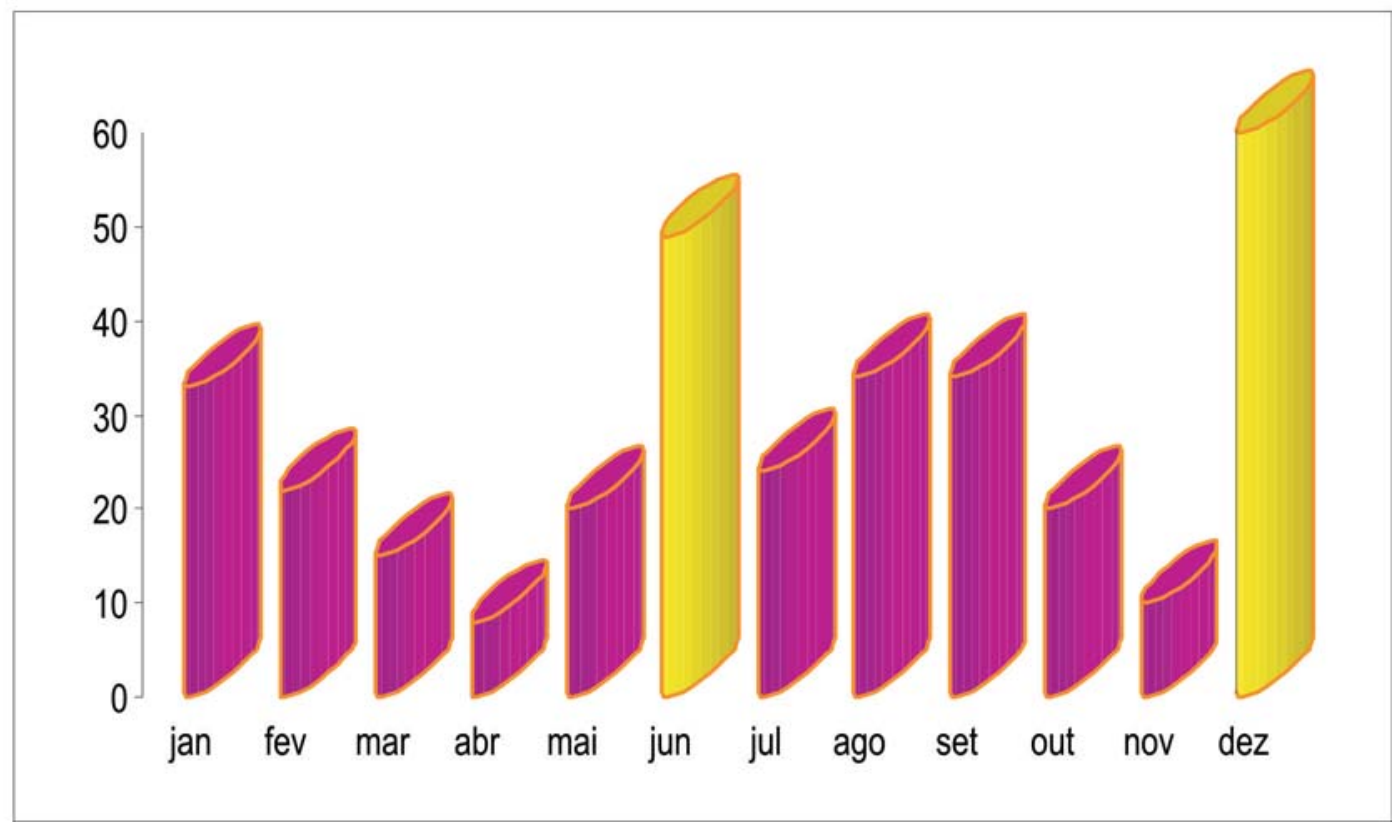

FIGURA 2 - DISTRIBUIÇÃO DAS FESTAS RELIGIOSAS NO CEARÁ

FONTE: www.ceará.gov.br/secult

Já o segundo gráfico nos permite a visualização regional da distribuição dessas festas, tendo ainda como elemento relevante, para a discussão dos aspectos contemporâneos, a força da devoção mariana (veneração à maternidade de Maria, mãe de Jesus). Já considerando a proposta de redefinição das regiões administrativas do estado, que passariam a padronizar 13 pólos regionais, conforme documento do Instituto de Pesquisas Econômicas do Ceara (IPECE).

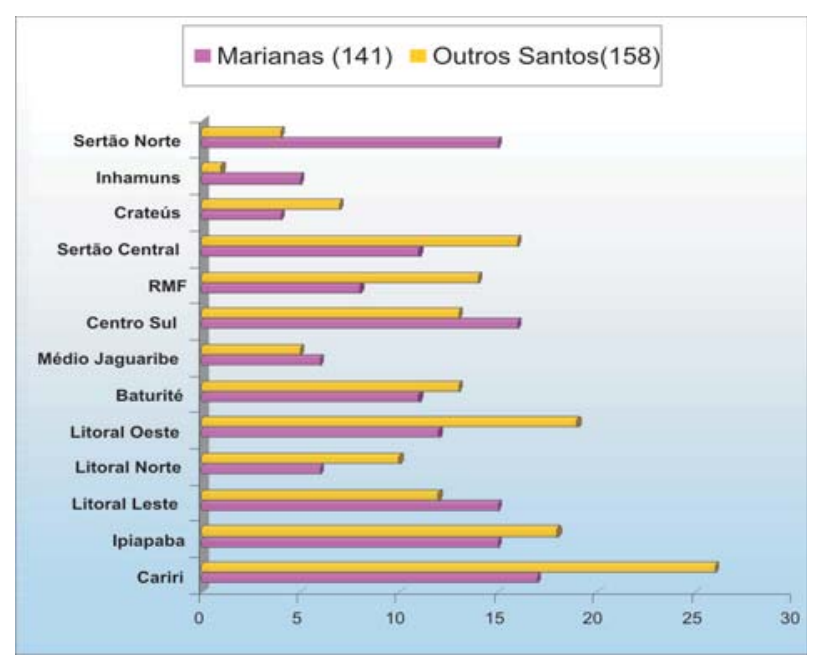

FIGURA 2 - DISTRIBUIÇÃO DAS FESTAS RELIGIOSAS NO CEARÁ

FONTE: www.ceará.gov.br/secult
A discriminação das festas marianas como uma particularidade bastante representativa do processo de carnavalização, justifica-se pelo alto teor simbólico presente nos rituais a essa divindade feminina. Algo significativo também se considerarmos a estrutura de gênero, na freqüência as igrejas cristãs, girando em torno de $75 \%$ de mulheres. Há, portanto, um primeiro fator, que demarca a "projeção paisagística" das festas. Trata-se de uma estratégia de visualidade e visibilidade francamente feminina.

Do ponto de vista anual, a Figura 02 nos fornece a expressividade dos meses junho e dezembro como aqueles mais favoráveis ao acontecer festivo. Quando associado à época das férias escolares (janeiro e julho) aparece um relevante período de festividades, que permitiria interligá-lo, no estado, a alta estação turística. Não fosse a permanente dificuldade em visualizar a criação e manutenção de estruturas fixas com finalidades sócio-culturais diversificadas.

Já do ponto de vista regional (Figura 03), mesmo com o destaque do Cariri em relação às outras "províncias" de festas religiosas, nota-se uma importante equiparação entre elas. Não existe uma área só concentradora das festas religiosas em detrimento da relevância das demais. Isso aponta, acima de tudo, que o planejamento turístico dessas localidades: 1- precisa interagir com a imagem cultural de um contingente 
(festeiro) vivencia períodos de festas ao longo de todo ano. Não em caráter tão especial e excludente como a oferta ingênua da festa tenderia a considerar; 2- pode e deve compor uma turistificação do evento em termos regionais; apostando na mudança de datas para evitar o choque de muitos eventos em um mesmo período. Principalmente, se fora do calendário religioso ou confessional, outras festividades comerciais ou cívicas "atrapalharem" este planejamento.

\section{RESULTADOS ALCANÇADOS EVIDENCIANDO A COMPLEXIDADE TURÍSTICA}

Por último, já estabelecendo um tratamento operatório que torna os Santuários carnavalescos espaços dialógicos (para visitação educativa) - e utilizando a vertente da desconstrução educacional de Antoni Colom (2004) - o texto propõe novas formas de inserção no circuito dos lugares turísticos. A significativa multiplicação de práticas locais e regionais dos processos carnavalescos ganha relevo na valorização do evento e projeção (paisagística) de sua efervescência. No que diz respeito ao Carnaval propriamente dito, Fortaleza não se constitui em um pólo de irradiação da modelagem dessa festa em escala nacional. Não há menção turística ou midiática a esse atrativo na cidade; muito embora as agremiações e o poder público estejam buscando caminhos para essa projeção.

Uma situação oposta pode ser encontrada a partir dos eventos de caráter religioso, distribuídos ao longo do ano, colocando assim gestão pública do Turismo em uma situação desafiadora: como oferecer alternativas a visitação de lazer em Fortaleza - ultrapassando os limites do Turismo de sol e praia - se os eventos culturais e religiosos (da cidade e do estado) se recusam organizarem-se como produto "turístico"? A complexidade da situação transparece a medida que se observa na manifestações religiosas - e no processo de carnavalização decorrente - um processo diametralmente oposto nessa alegada "recusa" ao Turismo. A prática turística recusada é aquela mesma patrocinada pelo poder público com políticas discriminatórias e excludentes do turismo no estado. Aquela que direciona o trade para o receptivo turístico internacional (que não ultrapassa $10 \%$ dos visitantes no Ceará) ou que elege, no governo estadual (gestão 2007-2010) a construção de um novo Centro de Convenções como a principal prioridade para o desenvolvimento do setor.

A festa de Nossa Senhora de Assunção é marcada por uma grande procissão interbairros que percorre aproximadamente oito quilômetros de extensão, entre a zona oeste da cidade e o centro, com destino a catedral metropolitana. Entre $14 \mathrm{~h} 00$ e $21 \mathrm{~h} 00$, centenas de grupos, paróquias, comunidades e movimentos pastorais desfilam ao longo da Avenida Castelo Branco (conhecida como Leste-Oeste), sendo acompanhada e atraindo atenção de fiéis, curiosos e participantes. A procissão é historicamente recente. E vem no bojo de outras manifestações católicas promovidas em parques, ginásios e ruas, como estratégia de exteriorização de uma efervescência, catolicismo institucional e popular. Para tanto, a liderança dos novos grupos pastorais e a midiática atividade global do Vaticano tem sido indispensáveis. Seja a visita do Papa ao Brasil (maio de 2007), seja a eleição do Cristo Redentor como uma das sete maravilhas do mundo moderno tem-se, na carnavalização dessa festa, a gestão articulada de estruturas que viabilizam seu complexo diálogo com as práticas turísticas.

De forma também representativa a Festa de lemanjá, na Praia do Futuro (leste da cidade), reunindo cerca de 70 terreiros de Umbanda (segundo os organizadores) e 100 mil pessoas, na manhã desse feriado municipal, denotava outra significativa estrutura de turistificação ignorada pelo planejamento do setor. A preocupação do poder público na versão do evento em 2006 era reduzir o índice de violência e assaltos coletivos ("arrastões") vividos na versão anterior da festa. Mas nos dois casos, mesmo diante da alta temporada do turismo internacional (mês de agosto), não se verificava na rede hoteleira, nem na rodoviária ou aeroporto, qualquer menção especial às manifestações religiosas de massa. Manifestações turísticas por excelência e destituídas de reconhecimento do setor. Em que medida a lógica da simplificação das políticas insiste em ignorar a complexidade dos fatos e processo?

As paisagens rituais que evidenciamos no estudo de caso - as festas de quinze de agosto na capital cearense - operam demonstrações compatíveis com a desconstrução dessa pretensa "teoria do planejamento turístico". Seu limite é buscar a modelagem de uma indústria do Turismo no Ceará a partir de soluções mirabolantes e impactos socioambientais irresponsáveis. Sempre generalizando uma parte do espaço turístico e ignorando todas as demais configurações de sua produção.

A Complexidade generaliza a teoria ao mesmo tempo em que a particulariza, isto é, a complexidade dessacralizou a teoria. Deixou de ser fundamental como verdade para ser democratizadora da verdade. A verdade já não é problema da ciência, mas sim da utilidade. A complexidade serve para explicar nossos 
OLIVEIRA, C. D. M. Carnavalização e Complexidade Turística...

interesses e para dar crédito às nossas necessidades. A desconstrução da teoria se encontra na generalização da mesma.

Nos termos dos desdobramentos da complexidade, Collom ainda nos lembra que

[...] a teoria do caos foi o duro golpe de misericórdia na sacralização da teoria; ela demonstra que não existe a ordem, nem sequer as bases onde assentar a narratividade sobre a ordem. Não existe a realidade a não ser como um fazer-se irreversível, sem passagem de volta; um fazer-se que, além do mais, é imprevisível, em que a complexidade aumenta por surgir das complexidades anteriores... (COLLOM, 2004, p. 127)

O desconhecimento da produção desses novos santuários reflete a teimosia da gestão cartesiana dos espaços públicos e do Turismo como um setor exclusivamente econômico. O fazer turístico, frente à carnavalização das práticas culturais, responde com estratégias caóticas a essa verdade teórica. Outras verdades são possivelmente mais emancipadoras e educativas. São essas que merecem planejamento qualitativo e envolvimento social; só delas podemos esperar um outro modelo (mais democrático) de desenvolvimento territorial.

Em termos conclusivos, o estudo explorou um sentido radicalmente geoeducacional das práticas festivas. É possível enxergar no contato das paisagens rituais com a complexidade do turismo, os novos propulsores de um ordenamento cultural para a metrópole cearense. O Carnaval agora ultrapassa o estágio de festa religiosa da raça, como falava Oswald de Andrade, e se transmuta em estratégia simbólica das praças (ícones paisagísticos da democracia direta); um espaçotempo de inclusão social, com sentido ritual. Algo que as políticas públicas mal conseguem entender. Que dirá administrar. Algo que precisa ser promovido com outras vertentes de interpretação; aquelas mais comprometidas com a construção de realidade do que com sua mera retratação. Estudos onde o futuro não seja apenas a repetição do passado, um museu de grandes novidades, nas palavras de outro poeta contemporâneo.

\section{REFERÊNCIAS}

ARAUJO, Hiram. Carnaval: Seis milênios de História. Rio de Janeiro: Gryphus, 2003.

BARBOSA, Elyana; BULCÃO, Marly. Bachelard, Pedagogia da Razão, Pedagogia da Imaginação. Petrópolis: Ed. Vozes, 2004.
BAZAN, Francisco G. Aspectos incomuns do sagrado. São Paulo: Paulus, 2002.

BELO, Ângela A. Culturas e Religiões: uma leitura fenomenológica. Bauru: Edusc, 1998.

BIGNAMI, Rosana. A imagem do Brasil no Turismo. Construção, desafios e vantagem competitiva. São Paulo: Aleph, 2002.

CEARÁ. Governo do Estado do Ceará. Disponível em: <http:// www.ceara.gov.br>. Acesso em: 23, 24 e 25/06/2007.

COLOM, Antoni J. A (des)construção do Conhecimento Pedagógico: Novas perspectivas para a educação. Porto Alegre. Artmed Editora, 2004.

COSTA, Benhur P. da. As relações entre os conceitos de Terrirório, Identidade e Cultura no Espaço Urbano: Por uma abordagem microgeográfica. In: ROSENDAHL, Z.; CORREA, R. L. (Org.). Geografia: Temas sobre a Cultura e Espaço. Rio de Janeiro: Ed.UERJ, 2005, p. 79 a 113.

ELIADE, Mircea. O sagrado e o profano. A essência das Religiões. São Paulo: Martins Fontes, 2001.

FERREIRA, Felipe. Inventando Carnavais: O surgimento do Carnaval Carioca no século XIX e outras questões carnavalescas. Rio de Janeiro: Editora da UERJ, 2005.

FERREIRA, Maria N. As Festas Populares e a Expansão do Turismo. A experiência Italiana. São Paulo: Arte \& Ciência Villipress. 2001.

IPECE. Disponível em: <http://www.ipece.gov.br>Acesso em: 01, 02, 03 e 04/07/2007.

LEFF, Enrique. Epistemologia Ambiental. São Paulo: Cortez, 2001.

LEFEBVRE, Henri. Da cidade à Sociedade Urbana. In: A Revolução Urbana. Belo Horizonte. Ed. UFMG, 2002. p. 15-32.

MARTIN-BARBERO, Jesus. Dos meios às mediações: comunicação, cultura e hegemonia. Rio de Janeiro, Editora UFRJ, 2003.

McDOWELL, Linda. A transformação da Geografia Cultural. In: GREGORY, D.; MARTIN, R.; SMITH, GRANHAN (Org.). Geografia Humana. Sociedade, Espaço e Ciência Social. Rio de Janeiro: Jorge Zahar Editor, 1996, p. 159-188.

MELO, José M. Carnaval: Das metrópoles brasileiras à aldeia global. Estudo de um fenômeno norte-sul de Folkmídia. In: $A$ Esfinge Midiática. São Paulo: Paulus 2004. p. 205-246.

OLIVEIRA, C. D. M. de. Geografia do Turismo na Cultura Carnavalesca: o Sambódromo do Anhembi. São Paulo: Paulistana, 2007.

C. D. M. de. Turismo Religioso no Brasil: Construindo um investimento sócio-cultural. In: TRIGO, L. G. G. et al. Análises Regionais e Globais do Turismo Brasileiro. São Paulo, 2005, p. 325-344. 
OLIVEIRA, C. D. M. Carnavalização e Complexidade Turística...

QUEIROZ, M. I. P. de. Carnaval Brasileiro: O vivido e o mito. São Paulo: Brasiliense, 1999.

SILVA, Aldo A. D. da; GALENO, Alex (Org). Geografia: Ciência do Complexus. Porto Alegre: Sulina, 2004.
TRAMONTE, Cristiana. O samba pede passagem: As estratégias e a ação educativa das escolas de samba. Petrópolis: Ed. vozes, 2001. 